\title{
Overview of Microanalysis Techniques for the Characterization of Concrete and Cement Materials.
}

\author{
B. J. Willenberg and L. A. Dempere \\ Major Analytical Instrumentation Center, University of Florida, Gainesville, FL 32611-6400
}

Understanding the diffusion and distribution of chlorine $(\mathrm{Cl})$ in concrete is a critical component in the evaluation of maintenance and life expectancy (durability) of steel reinforced concrete structures. The typical method of evaluation of these structures still uses analytical wet chemistry techniques that are costly, time-consuming, create hazardous waste, provide no information on the distribution of $\mathrm{Cl}$ at the microscale, and destroy the samples in the process.

The chemistry of large sections (on the order of several $\mathrm{cm}^{3}$ ) is currently evaluated down to the ppm level. Diffusion profiles and diffusion coefficients are generated with this data to estimate the time to corrosion in steel reinforced concrete structures. A value of approximately $300 \mathrm{ppm}$ of $\mathrm{Cl}$ present at the rebar-concrete interface is currently considered the threshold level of [Cl] to initiate corrosion of the steel rebar.

The use of microanalysis techniques in the evaluation of $\mathrm{Cl}$ in concrete has been attempted using microanalysis [1]. The aim has been to develop a methodology that provides faster output, higher spatial resolution of the diffusion profile, and distribution of $\mathrm{Cl}$ at the microscale. The expectation is to obtain all this information at a lower cost without generating hazardous waste or destroying the sample.

Reduction in cost for analyzing $\mathrm{Cl}$ diffusion and distribution, in real-world concrete samples, using microanalysis instrumentation depends on the instrument capabilities such as the speed of data collection, available automation and the number of samples that can be loaded simultaneously into the instrument. The number of data points collected also strongly impacts the time of analysis per sample.

The techniques we are evaluating in our studies of diffusion of $\mathrm{Cl}$ in cement and concrete are Energy Dispersive Spectroscopy (EDS), Wavelength Dispersive Spectrometry (WDS) and micro $\mathrm{X}$-Ray Fluorescence ( $\mu$-XRF). The sample preparation requirements and rapid speed of analysis are the main strengths of EDS. The key advantage of WDS is a lower limit of detection (minimum concentration that can be detected, $\sim 100 \mathrm{ppm}$ ). Micro-XRF offers both, minimal sample preparation, fast speed of analysis and the potentially the lowest limit of detection $(\sim 10$ 's of ppm). The biggest limitation of EDS is the high limit of detection ( 1,000 ppm) while WDS requires samples to be polished to a mirror finish (scratches $\leq 1 \mu \mathrm{m}$ ); both techniques require the sample to be conductive. A careful selection of the $\mathrm{x}$-ray source must be done for $\mu$-XRF to 
ensure the generation of the characteristic x-ray signal of interest (e.g. $\mathrm{Cl} \mathrm{K}_{\alpha}$ ) without the introduction of overlapping signals from the x-ray source (tube lines).

Our preliminary results corroborate that the concentration and distribution of $\mathrm{Cl}$ is quite heterogeneous across the concrete microstructure. EDS data might prove to be adequate to provide most of the data required for the generation of diffusion profiles, and is expected to provide valuable $\mathrm{Cl}$ distribution $\mathrm{x}$-ray maps (figure 1). This study is intended to generate comparative data from all three techniques described above. Our goal is to establish the most practical microanalysis route for characterization of concrete, to replace the currently used analysis techniques, and to provide information describing $\mathrm{Cl}$ distribution and transport at microscale which can then be used to improve the current models of $\mathrm{Cl}$ behavior in concrete.

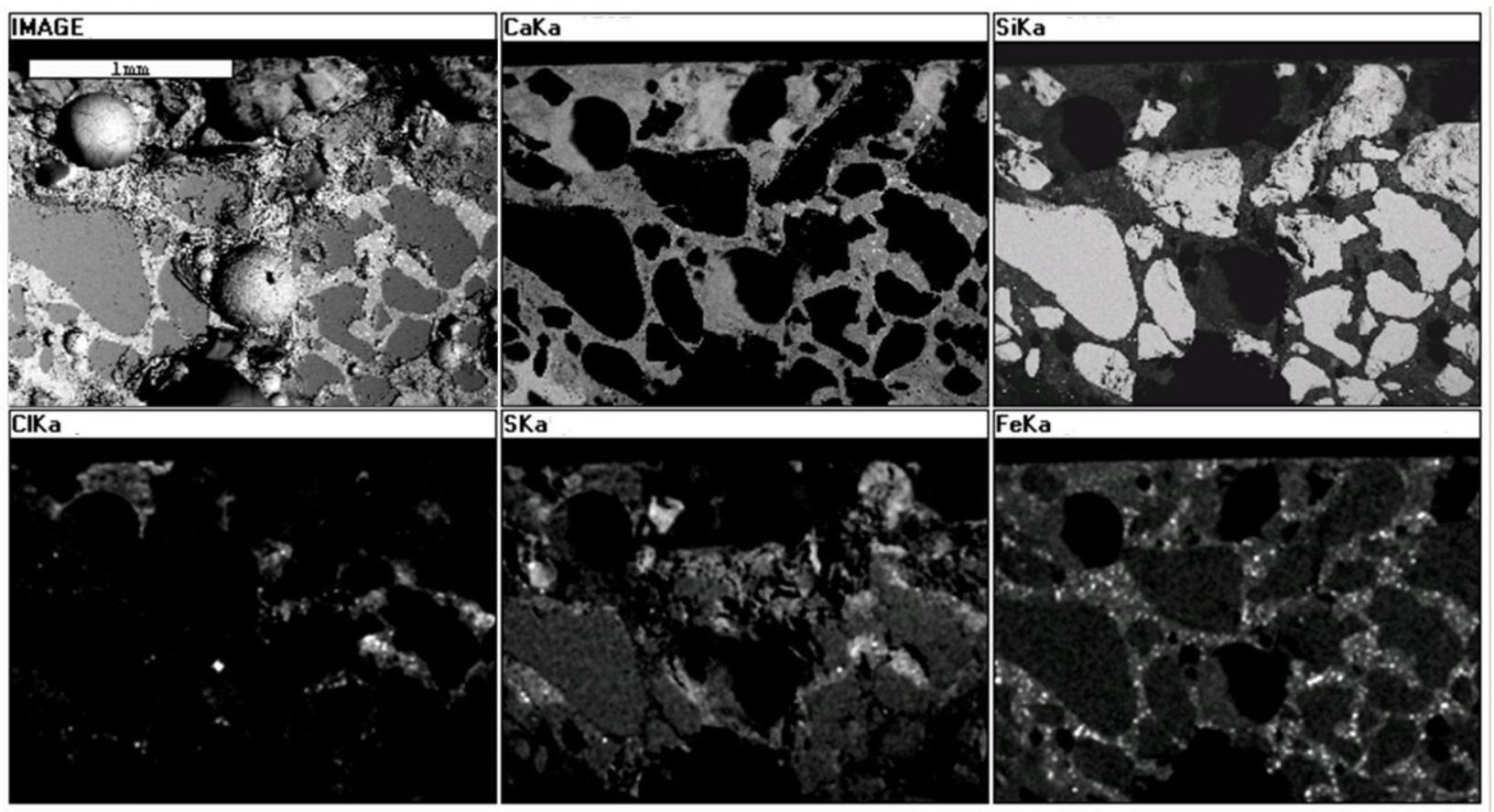

Figure 1. Low magnification (50X) x-ray map showing the distribution of $\mathrm{Ca}, \mathrm{Si}, \mathrm{Cl}, \mathrm{S}$ and $\mathrm{Fe}$ in a concrete sample. The data was collected using a JEOL JSM 6400 at $15 \mathrm{KV}$ equipped with an Oxford Instruments EDS Link ISIS system (version 3.35). Images were processed for quality purposes with filters and imaging tools available in the Link ISIS software.

References:

[1] D. More and K.A. Yamada, Journal of Advanced Concrete Technology 5(3) (2007)285-298. 